\title{
High Ratio of Myeloid Dendritic Cells to Plasmacytoid Dendritic Cells in Blood of Patients With Acute Coronary Syndrome
}

\author{
Takashi Fukunaga, MD; Hirofumi Soejima, MD; Atsushi Irie, PhD*; Ryuichiro Fukushima, MD; \\ Yoko Oe, MD; Hiroaki Kawano, MD; Hitoshi Sumida, MD; Koichi Kaikita, MD; \\ Seigo Sugiyama, MD; Yasuharu Nishimura, MD*; Hisao Ogawa, MD
}

\begin{abstract}
Background: Dendritic cells (DCs) stimulate T-cells to participate in the inflammatory processes that promote the destruction of vulnerable plaques. The relationship between circulating levels of myeloid DCs (mDCs) and plasmacytoid DCs (pDCs) in patients with acute coronary syndrome (ACS) was evaluated.

Methods and Results: Blood samples were obtained from 39 patients with ACS, 41 patients with stable angina pectoris (SAP) and 43 controls. The proportion of mDCs tended to be lower in the ACS group than in the SAP group and controls. Interleukin-12 levels associated with mDCs were significantly higher in the ACS group than in control group. The proportion of pDCs was significantly lower in the ACS groups than in the other two groups. Interferon- $\alpha$ levels secreted by pDCs, however, were not significantly different among the 3 groups. The ratio of $\mathrm{mDCs}$ to $\mathrm{pDCs} \geq 4$ is an important value for distinguishing ACS from SAP patients and control patients through receiver operating characteristic analysis (sensitivity; $85.0 \%$, specificity; $83.4 \%$ ).

Conclusions: The ratio of mDCs to pDCs may be a useful marker for detecting ACS and the existence of vulnerable plaques. (Circ J 2009; 73: 1914-1919)
\end{abstract}

Key Words: Acute coronary syndrome; Interferon- $\alpha$; Interleukin-12; Myeloid dendritic cells; Plasmacytoid dendritic cells

$\mathbf{I}$ mmune cells dominate early atherosclerotic lesions, while their effecter molecules accelerate progression of the lesions, and activation of inflammation can elicit acute coronary syndrome (ACS). ${ }^{1-3} \mathrm{~T}$-cells predominate at the shoulder of atherosclerotic plaques and participate in the inflammatory processes that promote the destruction of existing collagen in vulnerable plaques. ${ }^{3,4}$ Elucidation of T-cell pathophysiology and the mechanisms of T-cells' expansion provides insights into the cause of ACS and T-cells' roles therein.5,6 Liuzzo et al suggested that monocyte activation in ACS represents a downstream effect of altered T-cells responses, characterized by the preferential production of interferon- $\gamma$ and implicated an important role for T-cells in ACS patients. ${ }^{7}$ We also reported higher numbers of interferon- $\gamma$-producing T-cells in the peripheral blood of patients with unstable angina pectoris (UAP) than in that with stable angina pectoris (SAP) and controls. ${ }^{8}$ Recent studies showed that the function of a proportion of T-cells is controlled by dendritic cells (DCs). DCs are antigen-presenting cells with the unique ability to initiate a primary immune response to certain antigens through the activation of naive T-cells. ${ }^{9,10}$ DCs colocalize with T-cells in atherosclerotic plaques, emphasizing their potential role in modulating T-cells function in vivo. ${ }^{11,12}$ DCs are also localized in atherosclerotic and ruptured plaques of carotid arteries and aortas. ${ }^{13-15}$ There are two DC subtypes with different functions: (1) myeloid DCs (mDCs), which express CD1c, CD11c, CD303 and CD141, and secrete interleukin (IL)-12 after stimulation; and, (2) plasmacytoid DCs (pDCs), which express CD123 and CD303, the IL-3 receptor $\alpha$-chain; these are the major source of interferon- $\alpha .{ }^{16}$ Little is known about the circulating levels of $\mathrm{mDCs}$ and $\mathrm{pDCs}$ in patients with ACS. We hypothesized that analysis of peripheral DCs in patients with ACS may help to delineate local and systemic mechanisms underlying the formation of vulnerable plaques and stable plaques.

\section{Editorial p 1799}

Methods
Study Population
The study subjects were 123 patients who underwent coro-
nary artery angiography at Kumamoto University Hospital,
Kumamoto, Japan. Thirty-nine patients with a diagnosis of
UAP or acute myocardial infarction (AMI) were included
in the ACS group ( 25 men and 14 women, age range from
46 to 85 years, mean $67 \pm 11$ years). Patients with AMI were
admitted within 4 hours of onset of symptoms. The diagno-

(Received December 25, 2008; revised manuscript received May 20, 2009; accepted May 21, 2009; released online July 31, 2009)

Department of Cardiovascular Medicine, *Department of Immunogenetics, Graduate School of Medical Sciences, Kumamoto University, Kumamoto, Japan

Mailing address: Hirofumi Soejima, MD, Department of Cardiovascular Medicine, Graduate School of Medical Sciences, Kumamoto University, 1-1-1 Honjo, Kumamoto 860-8556, Japan. E-mail: yuuki@gpo.kumamoto-u.ac.jp

All rights are reserved to the Japanese Circulation Society. For permissions, please e-mail: cj@j-circ.or.jp 
Table 1. Clinical Characteristics of the Study Population

\begin{tabular}{|c|c|c|c|c|c|}
\hline & $\begin{array}{l}\text { Control subjects } \\
\qquad(\mathrm{n}=43)\end{array}$ & $\begin{array}{l}\text { ACS group } \\
(\mathrm{n}=39)\end{array}$ & $\begin{array}{l}\text { SAP group } \\
(\mathrm{n}=41)\end{array}$ & $\begin{array}{c}\text { P value } \\
\text { (comparison between } \\
\text { ACS and SAP groups) }\end{array}$ & $\begin{array}{c}\text { P value } \\
\text { (comparison } \\
\text { among } 3 \text { groups) }\end{array}$ \\
\hline Age (year) & $64 \pm 13$ & $67 \pm 11$ & $68 \pm 19$ & 0.58 & 0.31 \\
\hline $\mathrm{M} / \mathrm{F}$ & $19 / 24$ & $25 / 14$ & $25 / 16$ & 0.82 & 0.11 \\
\hline \multicolumn{6}{|l|}{ Coronary risk factor } \\
\hline Hyperlipidemia & $22(51 \%)$ & $31(79 \%)$ & $23(56 \%)$ & 0.0279 & 0.01 \\
\hline Hypertension & $21(49 \%)$ & $21(54 \%)$ & $26(63 \%)$ & 0.48 & 0.43 \\
\hline Current smoker & $9(21 \%)$ & $9(23 \%)$ & $8(20 \%)$ & 0.051 & 0.91 \\
\hline Diabetes mellitus & $9(21 \%)$ & $25(64 \%)$ & $19(46 \%)$ & 0.12 & 0.0002 \\
\hline White blood cell (cell/ $\mu \mathrm{l})$ & $5,586 \pm 1,432$ & $6,358 \pm 1,957$ & $5,930 \pm 1,920$ & 0.33 & 0.23 \\
\hline Granulocyte (\%) & $54.9 \pm 8.1$ & $60.3 \pm 9.3$ & $58.4 \pm 10.6$ & 0.40 & 0.0375 \\
\hline Lymphocytes (\%) & $35.7 \pm 8.7$ & $29.4 \pm 8.3$ & $30.8 \pm 9.3$ & 0.51 & 0.0044 \\
\hline Monocyte $(\%)$ & $5.9 \pm 1.5$ & $6.1 \pm 2.0$ & $6.2 \pm 2.0$ & 0.76 & 0.78 \\
\hline hs-CRP (mg/dl) & $0.12 \pm 0.17$ & $0.69 \pm 0.88$ & $0.24 \pm 0.34$ & 0.0042 & 0.0001 \\
\hline IL-12 (pg/ml) & $0.171 \pm 0.195$ & $0.874 \pm 1.830$ & $0.507 \pm 0.761$ & 0.56 & 0.0013 \\
\hline Interferon- $\alpha(\mathrm{pg} / \mathrm{ml})$ & $3.722 \pm 4.442$ & $1.807 \pm 2.220$ & $2.252 \pm 1.736$ & 0.73 & 0.11 \\
\hline \multicolumn{6}{|l|}{ Medication on admission } \\
\hline Aspirin & $17(40 \%)$ & $18(46 \%)$ & $29(71 \%)$ & & \\
\hline Angiotensin converting enzyme inhibitors & $3(7 \%)$ & $5(13 \%)$ & $4(10 \%)$ & & \\
\hline Angiotensin II type 1 receptor blockers & $11(26 \%)$ & $5(13 \%)$ & $4(10 \%)$ & & \\
\hline Nitrate/Nitrite & $4(9 \%)$ & $4(10 \%)$ & $10(24 \%)$ & & \\
\hline$\beta$-blockers & $5(12 \%)$ & $7(18 \%)$ & $6(15 \%)$ & & \\
\hline Calcium channel blockers & $22(51 \%)$ & $16(41 \%)$ & $29(71 \%)$ & & \\
\hline Diuretics & $0(0 \%)$ & $5(13 \%)$ & $2(5 \%)$ & & \\
\hline Statins & $11(26 \%)$ & $17(44 \%)$ & $19(46 \%)$ & & \\
\hline
\end{tabular}

Data are mean $\pm \mathrm{SD}$ or median $\left(25-75^{\text {th }}\right.$ percentile range). Hypertension was defined as systolic blood pressure $\geq 140 \mathrm{mmHg}$ and/or diastolic blood pressure $\geq 90 \mathrm{mmHg}$. Diabetes mellitus was defined as a fasting plasma glucose $126 \mathrm{mg} / \mathrm{dl}$ or higher or treatment with either insulin or hypoglycemic agents. Hypercholesterolemia was defined as treatment with hypolipidemic agents such as statin, or serum blood cholesterol levels $220 \mathrm{mg} / \mathrm{dl}$ or higher.

ACS, acute coronary syndrome; SAP, stable angina pectoris; hs-CRP, high sensitivity C-reactive protein; IL, interleukin.

sis of AMI was based on the presence of typical chest pain persisting for $\geq 30 \mathrm{~min}$, ST-segment elevation of $>0.2 \mathrm{mV}$ in $\geq 2$ contiguous leads on a standard 12-lead electrocardiogram, and elevation of serum creatine kinase (CK)-MB isoenzyme level to greater than twice the upper limit of the normal range. The diagnosis of UAP [Braunwald's class II $\mathrm{B}$ or III B] was based on the presence of chest symptoms at rest associated with transient ischemic ST-segment shifts and a normal serum level of CK-MB isoenzyme. ${ }^{17}$ Forty-one patients were diagnosed with SAP (25 men and 16 women, age range from 46 to 85 years, mean $68 \pm 9$ years). SAP patients were typified by long-term, stable angina of at least three months duration, and a positive exercise test. In addition, SAP patients were defined as those without angina episodes at rest and without previous myocardial infarction, but with angiographically documented organic stenosis of $>75 \%$ in at least one of the major coronary arteries. Forty-three patients with normal coronary parameters were included in the control group (19 men and 24 women, age range from 39 to 81 years, mean $64 \pm 13$ years). All controls underwent diagnostic cardiac catheterization because of a history of chest pain with multiple risk factors and/or an electrocardiographic abnormality. The coronary angiograms of the controls revealed no coronary organ stenosis $(<25 \%)$ or coronary spasm after intracoronary injection of acetylcholine. Exclusion criteria were non-cardiac diseases that might interfere with our analysis: acute or chronic infections, malignancies, autoimmune diseases, hyperthyroidism and medication with immunosuppressive agents. The institutional ethics committee of the Kumamoto University approved the study, and informed consent was obtained from all patients and control subjects.

\section{Blood Sampling}

ACS, SAP and control groups donated peripheral blood samples on admission, taken by sterile venipuncture using a 21-gauge needle and collected into heparinized and plain vacutainers. Two $\mathrm{ml}$ of blood was drawn into a heparinized vacutainer to measure the percentages of CD1c-, CD303and CD141-positive DCs. Serum IL-12 and interferon- $\alpha$ levels were measured using an enzyme-linked immunosorbent assay. Serum high-sensitivity C-reactive protein (hsCRP) levels were quantified using immunonephelometry. ${ }^{18}$

\section{Identification of DCs by Fluorescence-Activated Cell Sorting (FACS)}

Whole peripheral blood samples were analyzed using the Blood Dendritic Cell Enumeration Kit (Miltenyi Biotec, Utrecht, The Netherlands) based on subset-specific blood DC antigens. ${ }^{10,19}$ Four-color flow cytometry (FACS Calibur, Becton Dickinson, Erembodegem, Belgium) was conducted using monoclonal antibodies against CD14, CD19, CD1c, CD303 and CD141 that were directly conjugated with fluorochromes (phycoerythrin-cyanine-5, fluorescein isothiocyanate and phycoerythrin), and data were analyzed with CellQuest software (Becton Dickinson). After exclusion of cell debris, granulocytes, B cells and monocytes, the $\mathrm{mDC}$-subset $1(\mathrm{mDC} 1)$ and $\mathrm{pDCs}$ were identified through their immunopositivity for CD1c and CD303 antibodies, respectively. The $\mathrm{mDC}$-subset $2(\mathrm{mDC} 2)$ was identified as immunopositive for CD141, but not CD303. In the present study, we treated $\mathrm{mDC} 1$ and $\mathrm{mDC} 2$ as $\mathrm{mDCs}$. The absolute numbers of blood DCs were calculated as the proportion of DCs in the leukocyte gate multiplied by absolute white blood cell count. 
A

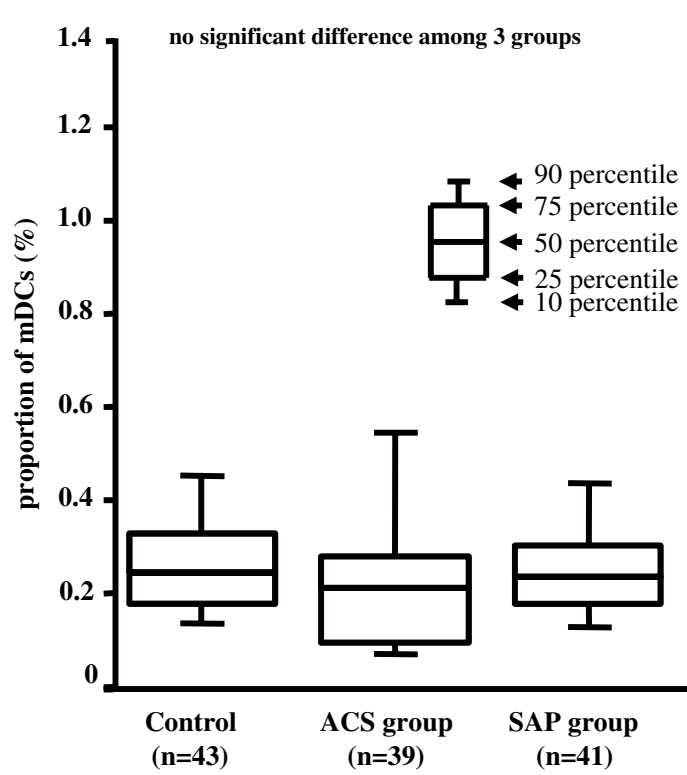

B

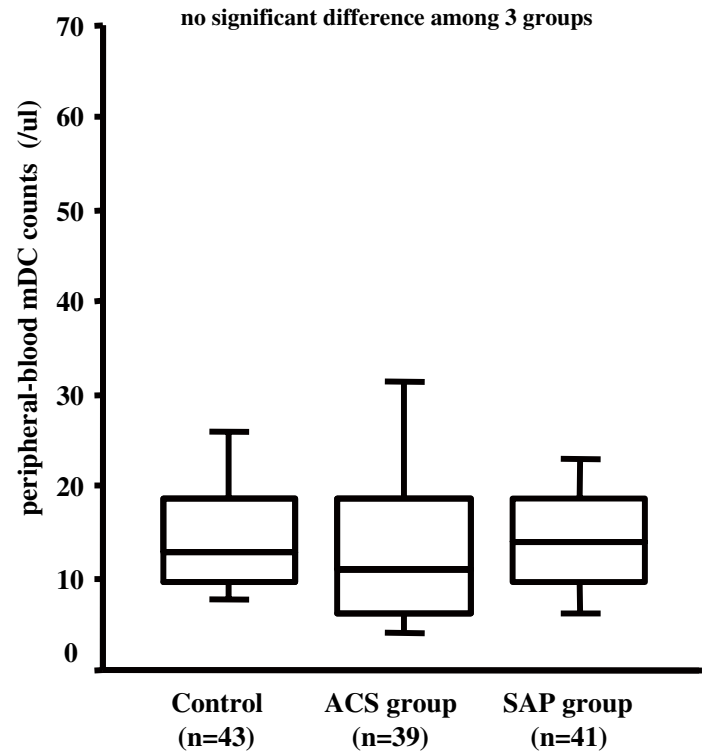

Figure 1. (A) Proportions of myeloid dendritic cells (mDCs) in acute coronary syndrome (ACS), stable angina pectoris (SAP) and control groups. (B) Absolute numbers of peripheral-blood mDCs in ACS, SAP and control groups.

A

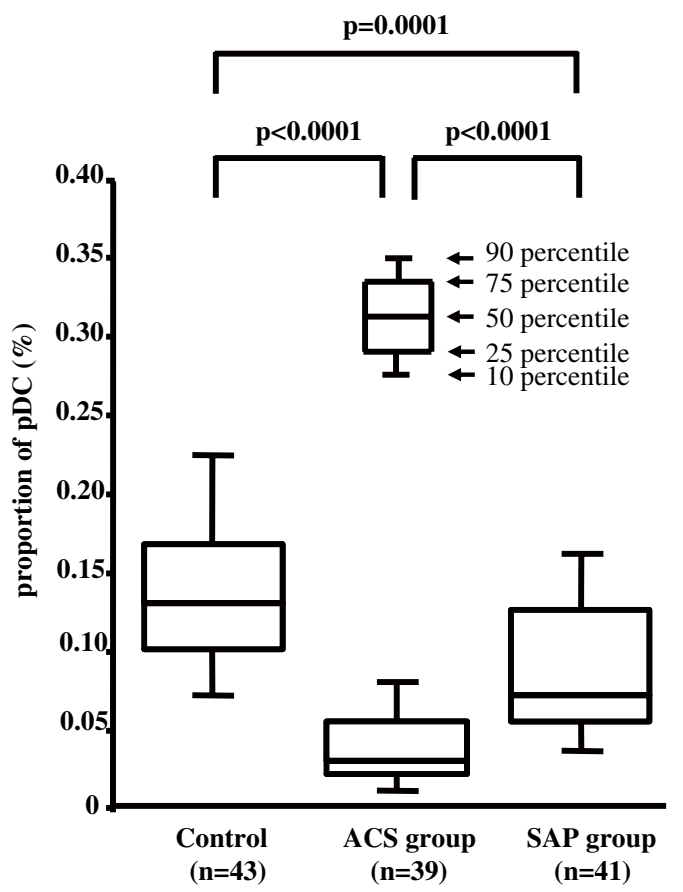

B

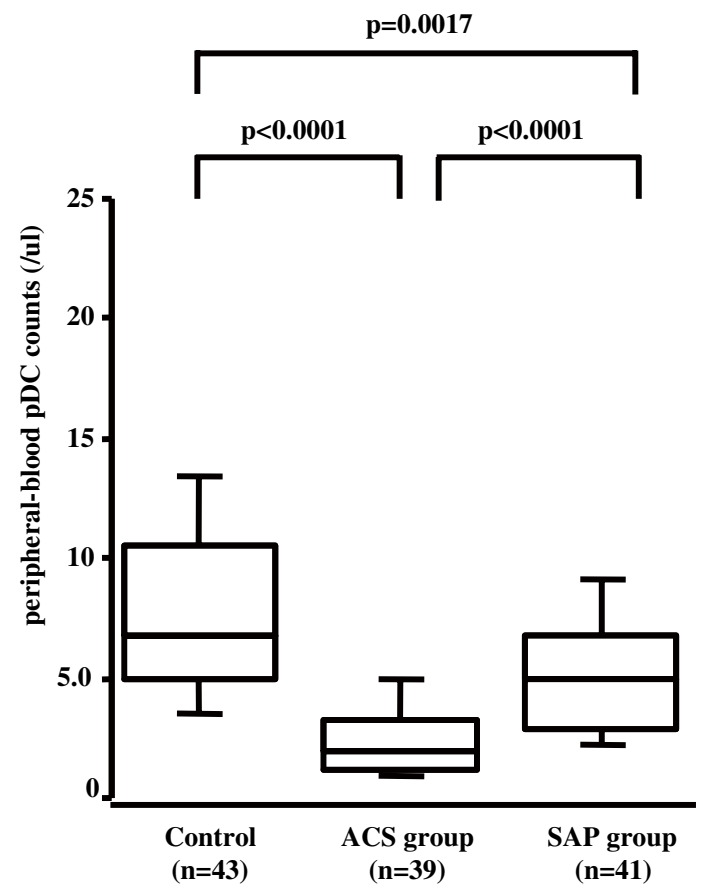

Figure 2. (A) Proportions of plasmacytoid dendritic cell (pDC) in acute coronary syndrome (ACS), stable angina pectoris (SAP) and control groups. (B) Absolute numbers of peripheral-blood pDC in ACS, SAP and control groups.

\section{Statistical Analysis}

Group data for normally distributed continuous variables were expressed as mean $\pm \mathrm{SD}$ and were compared using one-way analysis of variance or t-test. Group data for continuous variables that did not show normal distribution were expressed as median (25-75 th percentile range) and compared using the Kruskal-Wallis test or Mann-Whitney's $\mathrm{U}$ test. Categorical data were expressed as frequencies and percentages. A $\mathrm{P}$ value of $<0.05$ was considered statistically significant. $\mathrm{P}$ values compared among 3 groups are shown in Table 1 and $\mathrm{P}$ values compared between 2 groups are shown in Figures 1-4 when there was a significant difference among 3 groups. Multiple logistic regression analysis was performed to elucidate the independent predictor of ACS. Sensitivity and specificity were calculated in order to determine the predictive value. In addition, receiver oper- 


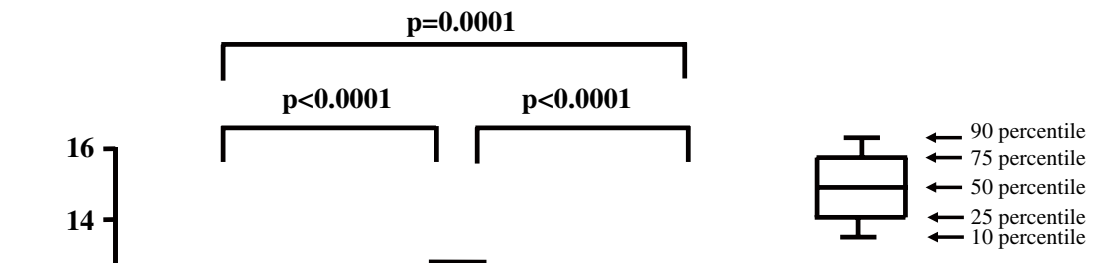

ating characteristic (ROC) analysis was carried out to determine the ideal cut-off for optimum specificity and sensitivity. Calculations were carried out using SPSS 15.0.1J statistical software.

\section{Results}

\section{Patient Characteristics}

The clinical characteristics of the ACS, SAP and control patients are listed in Table 1. All patients were matched for age, gender and frequency of coronary risk factors, except for hyperlipidemia and diabetes mellitus. We also compared patient characteristics between the ACS and SAP groups. There were no significant differences in the patient characteristics, except for hyperlipidemia, between the 2 groups.

\section{mDCs and pDCs}

There was no significant difference in absolute lymphocyte numbers among patients with ACS $(n=39)$, those with SAP $(n=41)$ and controls $(n=43)$. The proportion of mDCs tended to be lower in the ACS group than in the SAP group and controls. (Figures 1A, B). On the other hand, the proportion and absolute numbers of peripheral pDCs was significantly lower in the ACS and SAP groups compared to controls (Figures 2A, B), and the proportion of peripheral pDCs was significantly lower in patients with ACS than in those with SAP (Figures 2A,B). Furthermore, the ratio of mDCs to pDCs in peripheral blood was significantly higher in the ACS and SAP groups than in controls (Figure 3), and it was significantly higher in the ACS group than in the SAP group (Figure 3).

\section{Serum Levels of hs-CRP, IL-12, and Interferon- $\alpha$}

Serum hs-CRP levels were significantly higher in the ACS and SAP groups than in the control group (Table 1), and were significantly higher in the ACS group than in the SAP group $(\mathrm{P}=0.004)$. Serum IL-12 levels were significantly higher in the ACS and SAP groups than in the control group, and tended to be higher in the ACS group than in the SAP group (Table 1). On the other hand, there were no sig-
Figure 3. Comparison of myeloid dendritic cell (mDC) to plasmacytoid dendritic cell (pDC) ratios among acute coronary syndrome (ACS), stable angina pectoris (SAP) and control groups.

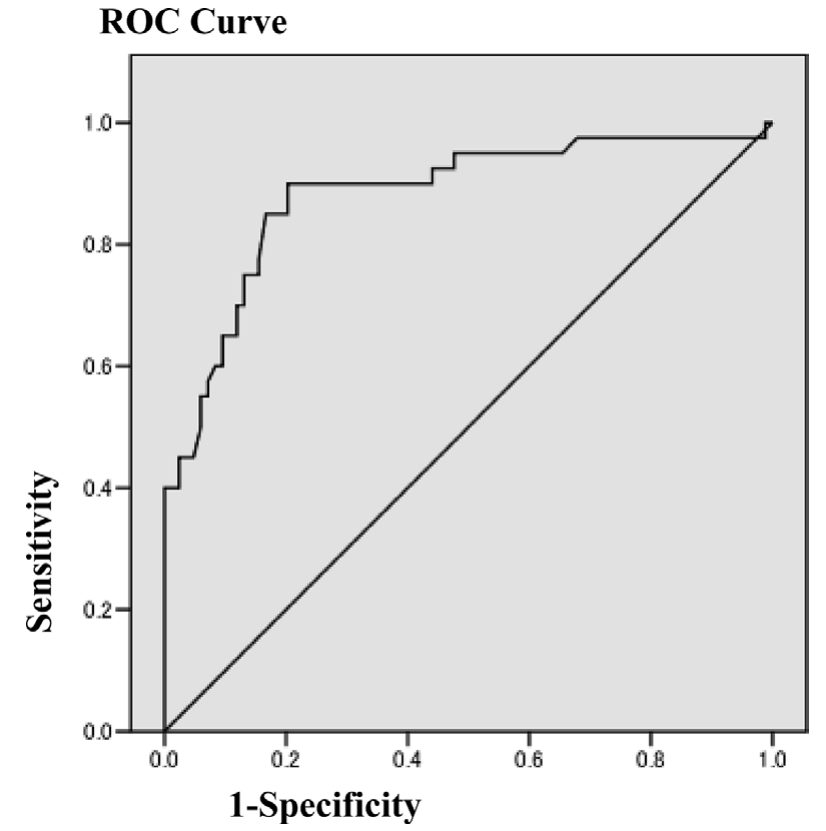

Figure 4. Plot showing receiver operating (ROC) characteristic curve for acute coronary syndrome for ratio of myeloid dendritic cells, to plasmacytoid dendritic cells.

Table 2. Multiple Logistic Regression Analysis of Hematological Findings of Independent Predictors of ACS

\begin{tabular}{lcc}
\hline & OR $(95 \% \mathrm{CI})$ & P value \\
\hline hs-CRP & $4.016(0.143-111.1)$ & 0.4140 \\
$\mathrm{mDC} / \mathrm{pDC}$ & $2.632(1.385-5.000)$ & 0.0031 \\
$\mathrm{IL}-12$ & $1.594(0.153-2.538)$ & 0.5164 \\
Granulocyte & $1.102(0.826-1.471)$ & 0.5100 \\
Max CK-MB & $1.066(0.956-1.189)$ & 0.2500 \\
Lymphocyte & $0.987(0.715-1.364)$ & 0.9377 \\
\hline
\end{tabular}

OR, odds ratio; $\mathrm{CI}$, confidence interval; $\mathrm{mDC}$, myeloid dendritic cell; $\mathrm{pDC}$, plasmacytoid dendritic cell; CK, creatine kinase. Other abbreviations see in Table 1. 
nificant differences in the serum interferon- $\alpha$ levels among the 3 groups (Table 1).

\section{ROC Analysis and Multiple Logistic Regressions Analysis}

An attempt to determine the optimum cut-off was made by calculating the area-under-the curve for ACS. From ROC analysis, the ratio of mDCs to pDCs $\geq 4$ had a sensitivity of $85.0 \%$ and a specificity of $83.4 \%$ for ACS (Figure 4). Multiple logistic regressions analysis revealed that the ratio of $\mathrm{mDC}$ to $\mathrm{pDC}$ is the only variable that was independently associated with ACS among CK-MB, Granulocyte, Lymphocytes, hs-CRP, ratio of $\mathrm{mDC}$ to $\mathrm{pDC}$ and IL-12 (Table 2).

\section{Discussion}

This study confirmed a lower proportion of $\mathrm{mDC}$ in the blood of patients with ACS compared with controls, in support of earlier findings. ${ }^{13,20}$ Previous studies also showed the recruitment of circulating $\mathrm{mDC}$ precursors into unstable atheroma and their crucial involvement in the (auto)immune mechanisms of atherosclerosis, as well as oxidized lowdensity lipoprotein promoting the maturation of $\mathrm{mDCs}$ and thus enabling T-cells activation in vitro. ${ }^{21-23}$ Yilmaz et al suggested that the increased recruitment of mDCs into unstable plaques and increased peripheral neutrophils and lymphocytes in patients with ACS might be responsible for decreased peripheral $\mathrm{mDCs}$ and relative lower percentage of mDCs. ${ }^{13}$

We found that serum IL-12 levels associated with mDCs tended to be higher in the ACS group compared with those in the SAP group and controls. These findings suggest that $\mathrm{mDCs}$ in peripheral blood are activated to secrete cytokines during ACS, despite the relative decrease in blood mDCs due to atheroma sequestering.

We did find, however, that $\mathrm{pDCs}$ were significantly lower in the blood of patients with ACS compared with controls, again supporting previous findings. ${ }^{13,20} \mathrm{We}$ analyzed interferon- $\alpha$ secreted from $\mathrm{pDCs}$ as a measure of $\mathrm{pDC}$ activation in the present study; however, there were no significant differences in the serum interferon- $\alpha$ levels among the 3 groups. Niessner et al also reported the level of pDCs in unstable plaque increased and pDC amplified cytolytic T-cells functions in unstable plaque. ${ }^{14,24}$ Furthermore, Banchereau et al suggested that this decrease in circulating pDCs reflects a drop in the production of pDCs precursors for $\mathrm{mDC}$ development by bone marrow.., 25

In the present study, the ratio of $\mathrm{mDCs}$ to $\mathrm{pDCs}$ was significantly higher in the blood of patients with ACS compared with that of SAP patients and controls, and the difference was significant among the three groups. We consider the ratio of mDCs to pDCs $\geq 4$ is an important value for ACS in ROC analysis. In this study, 34 of 39 ACS patients (87.2\%), 11 of 41 SAP patients (26.8\%), and 3 of 43 controls $(6.9 \%)$ showed an $\mathrm{mDCs}: \mathrm{pDCs}$ ratio $\geq 4$. The ratio of $\mathrm{mDCs}$ to $\mathrm{pDCs} \geq 4$ had a sensitivity of $85.0 \%$ and a specificity of $83.4 \%$ for ACS in this study. This ratio might therefore provide a useful marker for distinguishing vulnerable from stable plaques. Therefore, a prospective study may need to be conducted in the future to confirm it.

Serum levels of the inflammatory biomarker hs-CRP predict cardiovascular risk and some reports demonstrated the elevated levels of hs-CRP levels in patients with ACS. ${ }^{26-28}$ The induction of CRP might require IL-12, IL-6 and tumor necrosis factor- $\alpha$. Circulating levels of these inflammatory cytokines have been reported to be increased in patients with ACS. Moreover, Van Vré EA et al reported that CRP in patients with cardiovascular disease can influence DC function during atherogenesis. ${ }^{29}$ The present study showed markedly elevated serum hs-CRP levels in ACS and SAP patients compared with controls. These data therefore indicate serum hs-CRP and IL-12 levels could be a potentially useful additional marker in patients with cardiovascular disease and DCs might play important roles in arteriosclerotic progress and rupture.

Shi et al reported that peripheral-blood mDCs increased in patients with coronary artery disease compared with the control group in men..$^{30}$ In this study, there was no significant difference in the frequency of DCs between men and women.

In conclusion, the ratio of circulating mDCs to pDCs can detect ACS and the existence of vulnerable plaques. Thus, analysis of human DCs in peripheral blood might provide a new therapeutic target in patients with coronary artery disease.

\section{Acknowledgments}

This study was supported in part by a grant-in-aid for Scientific Research (No. C20590829) from the Ministry of Education, Science, and Culture in Japan, a grant from Japan Arteriosclerosis Prevention Fund, Japan and Japan Heart Foundation Grant For Research on Arteriosclerosis Update, Tokyo, Japan.

\section{References}

1. Libby P. Inflammation in atherosclerosis. Nature 2002; 420: 868 874.

2. Youssef AA, Chang LT, Hang CL, Wu CJ, Cheng CI, Yang CH, et al. Level and value of interleukin-18 in patients with acute myocardial infarction undergoing primary coronary angioplasty. Circ J 2007; 71: $703-708$.

3. Kruk M, Przyłuski J, Kalińczuk Ł, Pregowski J, Deptuch T, Kadziela $\mathrm{J}$, et al; ANIN Myocardial Infarction Registry Group. Association of non-specific inflammatory activation with early mortality in patients with ST-elevation acute coronary syndrome treated with primary angioplasty. Circ J 2008; 72: 205-211.

4. Shah PK. Mechanisms of plaque vulnerability and rupture. J Am Coll Cardiol 2003; 41(Suppl S): 15S-22S.

5. De Palma R, Del Galdo F, Abbate G, Chiariello M, Calabro R, Forte $\mathrm{L}$, et al. Patients with acute coronary syndrome show oligoclonal T-cell recruitment within unstable plaque: Evidence for a local, intracoronary immunologic mechanism. Circulation 2006; 113: 640-646.

6. Frostegard J, Ulfgren AK, Nyberg P, Hedin U, Swedenborg J, Andersson U, et al. Cytokine expression in advanced human atherosclerotic plaques: Dominance of pro-inflammatory (Th1) and macrophage-stimulating cytokines. Atherosclerosis 1999; 145: 33-43.

7. Liuzzo G, Goronzy JJ, Yang H, Kopecky SL, Holmes DR, Frye RL, et al. Monoclonal T-cell proliferation and plaque instability in acute coronary syndromes. Circulation 2000; 101: 2883-2888.

8. Soejima H, Irie A, Miyamoto S, Kajiwara I, Kojima S, Hokamaki J, et al. Preference toward a T-helper type 1 response in patients with coronary spastic angina. Circulation 2003; 107: 2196-2200.

9. Banchereau J, Steinman RM. Dendritic cells and the control of immunity. Nature 1998; 392: 245-252.

10. MacDonald KP, Munster DJ, Clark GJ, Dzionek A, Schmitz J, Hart DN. Characterization of human blood dendritic cell subsets. Blood 2002; 100: 4512-4520.

11. Lord RS, Bobryshev YV. Clustering of dendritic cells in athero-prone areas of the aorta. Atherosclerosis 1999; 146: 197-198.

12. Bobryshev YV, Lord RS. Mapping of vascular dendritic cells in atherosclerotic arteries suggests their involvement in local immuneinflammatory reactions. Cardiovasc Res 1998; 37: 799-810.

13. Yilmaz A, Lochno M, Traeg F, Cicha I, Reiss C, Stumpf C, et al. Emergence of dendritic cells in rupture-prone regions of vulnerable carotid plaques. Atherosclerosis 2004; 176: 101-110.

14. Niessner A, Sato K, Chaikof EL, Colmegna I, Goronzy JJ, Weyand CM. Pathogen-sensing plasmacytoid dendritic cells stimulate cytotoxic T-cell function in the atherosclerotic plaque through interferonalpha. Circulation 2006; 114: 2482-2489. 
15. Bobryshev YV. Dendritic cells in atherosclerosis: Current status of the problem and clinical relevance. Eur Heart J 2005; 26: 1700 - 1704.

16. Arpinati M, Chirumbolo G, Urbini B, Perrone G, Rondelli D, Anasetti C. Role of plasmacytoid dendritic cells in immunity and tolerance after allogeneic hematopoietic stem cell transplantation. Transpl Immunol 2003; 11: 345-356.

17. Braunwald E. Unstable angina: A classification. Circulation 1989; 80: $410-414$.

18. Rifai N, Tracy RP, Ridker PM. Clinical efficacy of an automated highsensitivity C-reactive protein assay. Clin Chem 1999; 45: 2136-2141.

19. Dzionek A, Fuchs A, Schmidt P, Cremer S, Zysk M, Miltenyi S, et al. BDCA-2, BDCA-3, and BDCA-4: Three markers for distinct subsets of dendritic cells in human peripheral blood. J Immunol 2000; 165: 6037-6046.

20. Van Vre EA, Hoymans VY, Bult H, Lenjou M, Van Bockstaele DR, Vrints CJ, et al. Decreased number of circulating plasmacytoid dendritic cells in patients with atherosclerotic coronary artery disease. Coron Artery Dis 2006; 17: 243-248.

21. Weis M, Schlichting CL, Engleman EG, Cooke JP. Endothelial determinants of dendritic cell adhesion and migration: New implications for vascular diseases. Arterioscler Thromb Vasc Biol 2002; 22: 1817 1823.

22. Alderman CJ, Bunyard PR, Chain BM, Foreman JC, Leake DS, Katz DR. Effects of oxidised low density lipoprotein on dendritic cells: A possible immunoregulatory component of the atherogenic micro-environment? Cardiovasc Res 2002; 55: 806-819.

23. Coutant F, Agaugue S, Perrin-Cocon L, Andre P, Lotteau V. Sensing environmental lipids by dendritic cell modulates its function. $J$ Immunol 2004; 172: 54-60.
24. Niessner A, Shin MS, Pryshchep O, Goronzy JJ, Chaikof EL, Weyand $\mathrm{CM}$. Synergistic proinflammatory effects of the antiviral cytokine interferon-alpha and Toll-like receptor 4 ligands in the atherosclerotic plaque. Circulation 2007; 116: 2043-2052.

25. Banchereau J, Briere F, Caux C, Davoust J, Lebecque S, Liu YJ, et al. Immunobiology of dendritic cells. Аппи Rev Immunol 2000; 18: $767-811$.

26. Albert MA, Danielson E, Rifai N, Ridker PM; PRINCE Investigators. Effect of statin therapy on C-reactive protein levels: The pravastatin inflammation/CRP evaluation (PRINCE): A randomized trial and cohort study. JAMA 2001; 286: 64-70.

27. Ridker PM; JUPITER Study Group. Rosuvastatin in the primary prevention of cardiovascular disease among patients with low levels of low-density lipoprotein cholesterol and elevated high-sensitivity C-reactive protein: Rationale and design of the JUPITER trial. Circulation 2003; 108: 2292-2297.

28. Ridker PM, Fonseca FA, Genest J, Gotto AM, Kastelein JJ, Khurmi NS, et al; JUPITER Trial Study Group. Baseline characteristics of participants in the JUPITER trial, a randomized placebo-controlled primary prevention trial of statin therapy among individuals with low low-density lipoprotein cholesterol and elevated high-sensitivity Creactive protein. Am J Cardiol 2007; 100: 1659-1664.

29. Van Vré EA, Bult H, Hoymans VY, Van Tendeloo VF, Vrints CJ, Bosmans JM. Human C-reactive protein activates monocyte-derived dendritic cells and induces dendritic cell-mediated T-cell activation. Arterioscler Thromb Vasc Biol 2008; 28: 511-518.

30. Shi H, Ge J, Fang W, Yao K, Sun A, Huang R, et al. Peripheral-blood dendritic cells in men with coronary heart disease. Am J Cardiol 2007; 100: 593-597. 